\title{
In vitro evaluation of temperature rise during different post space preparations
}

\author{
Hakan Gokturk ${ }^{1}$, Ismail Ozkocak ${ }^{1}$, Mehmet Murat Taskan ${ }^{2}$, Fatma Aytac ${ }^{3}$, \\ Emine Sirin Karaarslan ${ }^{3}$
}

Correspondence: Dr. Hakan Gokturk

Email: gokturk82@hotmail.com

\begin{abstract}
'Department of Endodontics, Faculty of Dentistry, Gaziosmanpaşa University, Tokat, Turkiye, ${ }^{2}$ Department of Periodontology, Faculty of Dentistry, Gaziosmanpaşa University, Tokat, Turkiye, ${ }^{3}$ Department of Restorative Dentistry, Faculty of Dentistry, Gaziosmanpaşa University, Tokat, Turkiye
\end{abstract}

\section{ABSTRACT}

Objective: The aim of this study was to evaluate temperature alterations on the outer root surface during post space preparation with six different post drills by using an infrared thermometer. Materials and Methods: Sixty extracted single-rooted human mandibular incisor teeth were used. After root canal obturation, the specimens were divided into six groups $(n=10)$. During post space preparation, the temperature rises were measured in the middle third of the roots using a noncontact infrared thermometer with a sensitivity of $0.1^{\circ} \mathrm{C}$. The temperature data were transferred from the thermometer to the computer and were observed graphically. Results: The maximum temperature rise was observed in Snowpost $2\left(29.95 \pm 10.2^{\circ} \mathrm{C}\right)(P<0.001)$, but there were no significant differences among Snowpost $2\left(29.95 \pm 10.2^{\circ} \mathrm{C}\right)$, Snowpost $1\left(24.6 \pm 8.0^{\circ} \mathrm{C}\right)$, and Relyx $2\left(17.68 \pm 9.1{ }^{\circ} \mathrm{C}\right)(P>0.05)$. Conclusions: Although water coolant used, the critical temperature rise was observed on the outer root surface in all post drill systems.

Key words: Endodontics, infrared thermometer, post space preparation, temperature increase, thermal analysis

\section{INTRODUCTION}

Endodontically treated teeth have an increased fragility due to previous restoration, decay, and endodontic access preparation ${ }^{[1-3]}$ or loss of moisture. ${ }^{[4]}$ Promoting the retention of the final restoration of such severely damaged teeth is usually treated with different post and core (CPC) systems. Thus, teeth were prepared for further treatment of a fixed partial denture or a crown. ${ }^{[5,6]}$ In the past, prefabricated posts made of precious alloys, stainless steel, or titanium were used. Nowadays, various types of fiber posts have been produced from the dental manufacturers, including quartz fiber posts, zirconia posts, glass fiber posts, and woven polyethylene fiber posts. ${ }^{[7-9]}$

Gates Glidden drills and Peeso reamers are used for post space preparation. Currently, for this purpose, various specific drills having different diameter are available. The Snowpost (Carbotech, Ganges, France) fiber post system has four finishing drills that have 1.0,1.2, 1.4, and $1.6 \mathrm{~mm}$ apical diameters.
The Relyx fiber post (3M ESPE, St. Paul, Minnesota, USA) system has drills with apical diameters of $1.1,1.3,1.6$, and $1.9 \mathrm{~mm}$. In addition, the Rebilda post (Voco, Cuxhaven, Germany) system has drills with apical diameters of $0.5,0.65,0.8$, and $1 \mathrm{~mm}$. Specific drills are recommended for use after root canal filling was removed by heated instruments or smallest drills.

The creation of the post space not only involves the partial remove of the root canal filling but sometimes requires the shaping of the canal space. ${ }^{[10]}$ One result

This is an open access article distributed under the terms of the Creative Commons Attribution-NonCommercial-ShareAlike 3.0 License, which allows others to remix, tweak, and build upon the work non-commercially, as long as the author is credited and the new creations are licensed under the identical terms.

For reprints contact: reprints@medknow.com

How to cite this article: Gokturk H, Ozkocak I, Taskan MM, Aytac F, Karaarslan ES. In vitro evaluation of temperature rise during different post space preparations. Eur J Dent 2015;9:535-41.

DOI: $10.4103 / 1305-7456.172630$ 
of post space preparation is temperature alteration on the root surface. ${ }^{[10,11]}$

The study by Eriksson and Albrektsson ${ }^{[12]}$ revealed the harmful effects of increased temperatures on the alveolar bone and periodontal ligament. They showed that a temperature rise of $10^{\circ} \mathrm{C}$ on the external root surface caused tooth ankyloses and bone resorption. ${ }^{[12]}$ Another study indicated that exposing the bone to a temperature of $53^{\circ} \mathrm{C}$ for $1 \mathrm{~min}$ interrupted the blood flow..$^{[13]}$ Exposure to a temperature of $43^{\circ} \mathrm{C}$ may result in protein denaturation in the periodontal ligament. ${ }^{[14]}$ Furthermore, the heat produced during post space preparation may influence the root surface and periodontal ligament. In addition, the adjacent bone may be adversely affected. ${ }^{[15,16]}$

There are various methods to measure tissue temperature in the mouth. ${ }^{[17,18]}$ Subgingival thermometers and thermocouples were used for this purpose. Other surface temperature measurement devices are noncontact infrared thermometers and infrared thermal imaging systems. Noncontact infrared thermometers measure the temperature in a short period and do not require other instruments or contact during the measurement. In addition, they do not cause infection, are less costly and do not require any preparation prior to the measurement. ${ }^{[19]}$ The Optris LS LT thermometer, which is a noncontact infrared thermometer, was used to measure temperature alterations. According to the manufacturer's instructions, the portable infrared thermometer allows selection of standard and close focus, and it has innovative sighting systems (cross and double lasers) to get sighting at any range.

To the best of our knowledge, there is no study was used a noncontact infrared thermometer to measure the heat increase of the external root surface in English literature. In this study, we aimed to investigate, in vitro, the temperature changes on the outer root surface during post space preparation with six different drills of three different post drill systems by a noncontact infrared thermometer. The null hypothesis was that the temperature rise is independent of drill design and diameter.

\section{MATERIALS AND METHODS}

The research proposal was submitted for review by the Tokat Clinical Research Ethics Committee of the Gaziosmanpaşa University of Turkey (14-KAEK-175), and the study design was approved.

\section{Teeth samples (sample selection)}

A total of 60 human mandibulary incisors with a single root canal and with anatomically similar root lengths were extracted for periodontal reasons. To confirm the canal anatomy, preoperative digital radiographs of each root were taken from two directions (mesiodistal and labiolingual). A closed apex was used for the present study. All teeth were stored at $4^{\circ} \mathrm{C}$ in physiologic saline until required.

\section{Root canal preparation and filling}

All calculus and other remnants were removed completely from the surfaces of the teeth. An access cavity was opened using high-speed hand tools. The working length (WL) was established as $1 \mathrm{~mm}$ short of the canal length with \#10 K file (VDW, Munich, Germany). The crowns were removed with diamond discs under water cooling, and a novel measurement of $14 \mathrm{~mm} \mathrm{WL}$ was obtained for each tooth. Thus, we had achieved standardized samples. The root canal was enlarged with Reciproc R25 (VDW, Munich, Germany) by using a torque-controlled motor (Silver Reciproc; VDW, Munich, Germany) in a reciprocating movement by the "Reciproc ALL" program. The canals were irrigated with $5 \%$ sodium hypochlorite solution ( $\mathrm{NaOCl}$ ) (Whitedentmed, Erhan Kimya, İzmir, Turkey). When the preparation of root canals was finished, $1 \mathrm{ml}$ of $17 \%$ ethylenediaminetetraacetic acid (Imicryl Ltd., Konya, Turkey) was used for $1 \mathrm{~min}$ and $10 \mathrm{ml}$ of $5 \% \mathrm{NaOCl}$ was used for smear layer removal. The root canals were then dried using paper points. The root canals were filled with 2Seal (epoxy-amine resin-based sealer VDW, Munich, Germany) and Gutta-percha points using the lateral condensation technique. Coronal access was coated with Cavit G (3M Espe, Seefeld, Germany), and the teeth were incubated for 5 days at $37^{\circ} \mathrm{C}$ in $100 \%$ humidity to allow the sealer to set entirely.

\section{Post space preparation}

The teeth were mounted vertically into self-curing $4 \mathrm{~mm}$ acrylic resin blocks in coronal third of roots, and the apical and middle third of the root surfaces were exposed. ${ }^{[11,15,20]}$ The length of exposed root surface was $11 \pm 0.1 \mathrm{~mm}$. The most similar sizes available among the drills were chosen and used in this study. For this reason, drills of varying sizes were used in the post drill system. The acrylic blocks were embedded in rubber dams (OptiDam ${ }^{\mathrm{TM}}$, Kerr Hawe SA, Bioggio, Switzerland) to avoid contact with water to the outer surface of the root during thermal measurement. This assembly is placed into a vice to prevent contact and heat exchange [Figure 1]. The Gates Glidden bur No: 2 


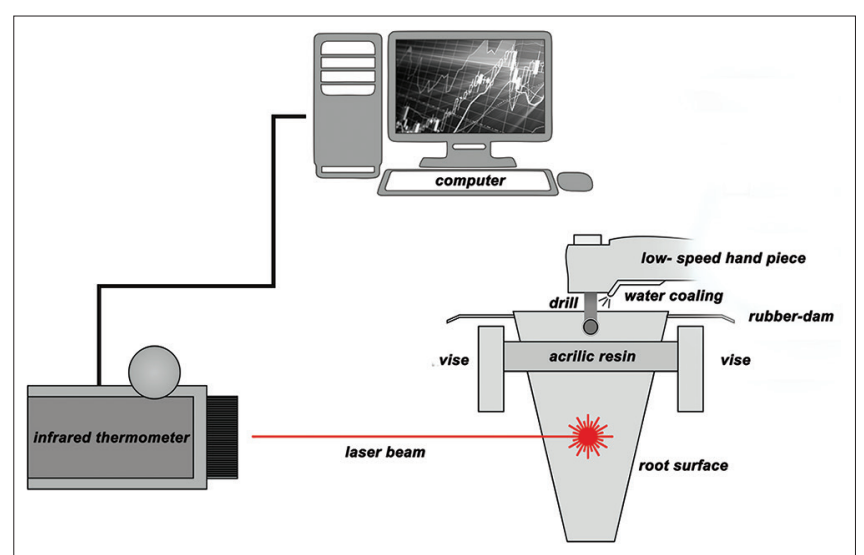

Figure 1: The experimental setup established to measure temperature increase in this study

(Mani Inc., Tochigi, Japan) (apical diameter $0.70 \mathrm{~mm}$ ) was used at $2000 \mathrm{rpm}$ under continuous water cooling ( $25 \mathrm{ml} / \mathrm{min}$ ) to remove coronal Gutta-percha until $9 \mathrm{~mm}$ in all of the roots. Then, the samples were randomly divided into six groups of 10 teeth each. The groups were follows [Figure 2]:

- Group 1: The Rebilda post size 10 drills (red; apical diameter $0.50 \mathrm{~mm}$ ) was used

- Group 2: The Rebilda post size 12 drills (green; apical diameter $0.65 \mathrm{~mm}$ ) was used

- Group 3: The Relyx Fiber post size 1 drill (white; apical diameter $1.1 \mathrm{~mm}$ ) was used

- Group 4: The Relyx Fiber post size 2 drills (yellow; apical diameter $1.3 \mathrm{~mm}$ ) was used

- Group 5: The Snowpost size 1 drill (white; apical diameter $1.0 \mathrm{~mm}$ ) was used

- Group 6: The Snowpost size 2 drills (yellow; apical diameter $1.2 \mathrm{~mm}$ ) was used.

All drills were used under continuous water cooling $(25 \mathrm{ml} / \mathrm{min})$ at $8000 \mathrm{rpm}$ rotation. A $9 \mathrm{~mm}$ post space was prepared in all root canals. Each drill was used inside the root canal for $30 \mathrm{~s}$. All post space preparations were completed parallel to root canal space by one operator. During post space preparation, a gentle force was applied.

\section{Temperature rise measurement}

During the post space preparations, the temperature changes were measured continuously using a noncontact infrared thermometer (Optris LS LT, Berlin, Germany) with a sensitivity of $0.1^{\circ} \mathrm{C}$ on the middle third of the mesial root surface. We examined five controls by measuring the temperature alterations in the control teeth for $30 \mathrm{~s}$ without any preparation. This was performed to determine whether the infrared thermometer caused any temperature change. The temperature alterations were transferred to

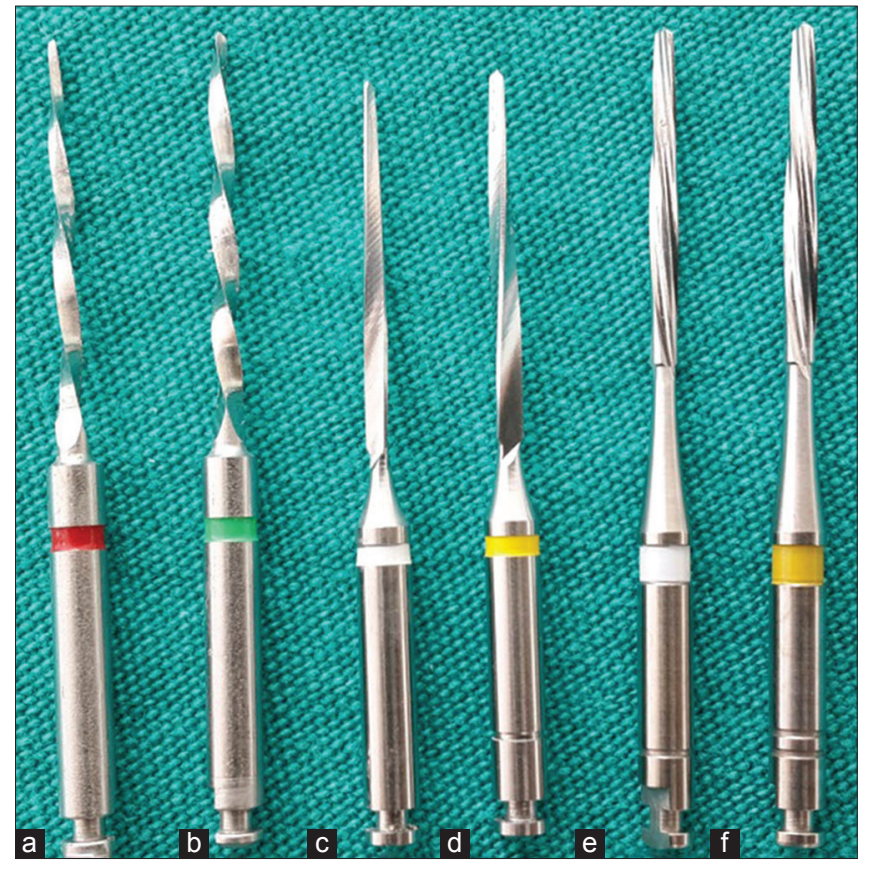

Figure 2: The drills used in the study (a) the Rebilda post size 10 drill, (b) the rebilda post size 12 drill, (c) the Relyx fiber post size 1 drill, (d) the Relyx fiber post size 2 drill, (e) the Snowpost size 1 drill, and (f) the Snowpost size 2 drill

a computer and were observed graphically. The maximum temperature rise for intervals at $0-10$, 11-20, and 21-30 s were recorded.

Shapiro-Wilk's test was used, and histogram and q-q plots were examined to assess the data normality. Two-way repeated measures ANOVA was used for time comparison according to groups and group effects, and the values are expressed as the mean \pm standard deviations. Analyses were conducted using commercial software (IBM SPSS Statistics 19, SPSS Inc., IBM Co., Somers, New York, USA). The level of statistical significance was set at 0.05 .

\section{RESULTS}

The mean temperature increases and standard deviations for the experimental groups are shown in Table 1 . The maximum temperature rise was observed in Snowpost $2\left(29.95 \pm 10.2^{\circ} \mathrm{C}\right)$ $(P<0.001)$, but there were no significant differences among Snowpost $2\left(29.95 \pm 10.2^{\circ} \mathrm{C}\right)$, Snowpost $1\left(24.6 \pm 8.0^{\circ} \mathrm{C}\right)$, and Relyx $2\left(17.68 \pm 9.1^{\circ} \mathrm{C}\right)(P>0.05)$. Although Rebilda $1\left(8.08 \pm 5.4^{\circ} \mathrm{C}\right)$ caused the lowest temperature rise, no significant differences were observed among Rebilda $1\left(8.08 \pm 5.4^{\circ} \mathrm{C}\right)$, Rebilda $2\left(12.85 \pm 7.2^{\circ} \mathrm{C}\right)$, and Relyx $1\left(12.73 \pm 5.8^{\circ} \mathrm{C}\right)$ $(P>0.05)$. Figures 3 and 4 show the results obtained in this experiment. 


\begin{tabular}{|c|c|c|c|c|}
\hline \multirow[t]{2}{*}{ Group } & \multicolumn{3}{|c|}{ Time intervals } & \multirow{2}{*}{$\begin{array}{l}\text { Overall } \\
\text { mean }\end{array}$} \\
\hline & $0-10 \mathrm{~s}$ & $11-20 \mathrm{~s}$ & $21-30 \mathrm{~s}$ & \\
\hline 1 & $8.9 \pm 6.2$ & $8.85 \pm 6.9$ & $6.5 \pm 5.8$ & $8.08 \pm 5.4^{*}$ \\
\hline 2 & $12.5 \pm 4.7$ & $15.2 \pm 10.8$ & $10.85 \pm 9.4$ & $12.85 \pm 7.2^{*}$ \\
\hline 3 & $11.1 \pm 7.3$ & $14.75 \pm 5.9$ & $12.35 \pm 5.6$ & $12.73 \pm 5.8^{*}$ \\
\hline 4 & $19.55 \pm 6.9$ & $21.5 \pm 13.0$ & $12 \pm 9.6$ & $17.68 \pm 9.1^{\dagger}$ \\
\hline 5 & $25.35 \pm 11.2$ & $31.1 \pm 12.1$ & $17.35 \pm 6.1$ & $24.6 \pm 8.0^{\dagger}$ \\
\hline 6 & $21.45 \pm 15.9$ & $40.7 \pm 12.9$ & $27.7 \pm 8.9$ & $29.95 \pm 10.2^{\dagger}$ \\
\hline $\begin{array}{l}\text { Overall } \\
\text { mean }(n=60)\end{array}$ & $16.48 \pm 10.9^{\ddagger}$ & $22.02 \pm 14.9^{\S}$ & $14.46 \pm 10.1$ & $17.65 \pm 10.6$ \\
\hline \multicolumn{5}{|c|}{$\begin{array}{l}\text { Group: } F=11.136, P<0.001 \text {, Time: } F=22.538, P<0.001 \text {, Group } \times \text { time: } F=4.294 \text {, } \\
P<0.001 \text {, }{ }^{*} \text { Differences between groups in terms of overall mean temperature } \\
\text { rise without consideration of time intervals, }{ }^{*} \text { Differences between three-time } \\
\text { intervals in terms of overall mean temperature rise without consideration of drills. } \\
\text { SDs: Standard deviations }\end{array}$} \\
\hline
\end{tabular}

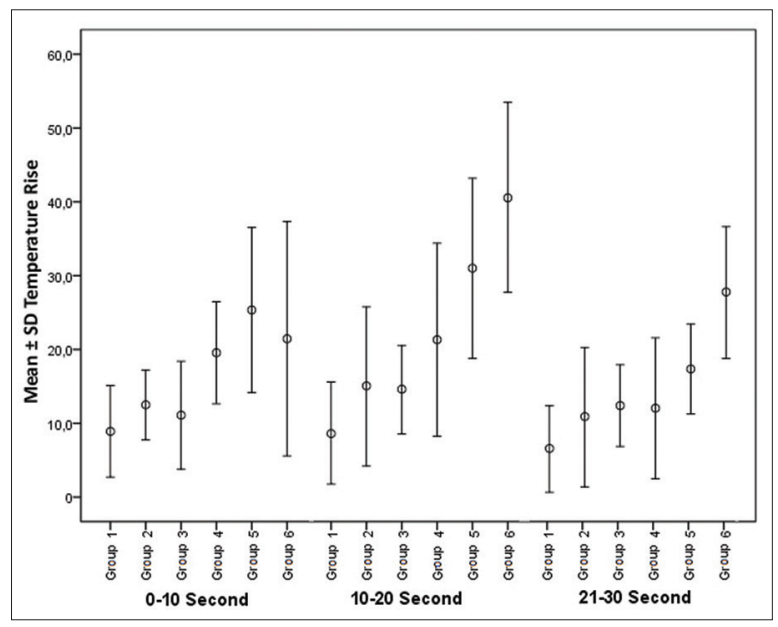

Figure 3: The mean temperature rises during the post space preparation

As a result of the statistical tests, group and time interactions were determined. When time intervals compared with the overall mean temperature rise without considering the groups, the significant maximum temperature rise was observed in the period from 11 to $20 \mathrm{~s}\left(22.02 \pm 14.9^{\circ} \mathrm{C}\right)$ compared to the other periods $(P<0.001)$. There were no significant differences between the period from 0 to $10 \mathrm{~s}\left(16.48 \pm 10.9^{\circ} \mathrm{C}\right)$ and the period from 21 to $30 \mathrm{~s}$ $\left(14.46 \pm 10.1^{\circ} \mathrm{C}\right)$, which had the lowest temperature rise $(P>0.05)$.

\section{DISCUSSION}

This in vitro study investigated the temperature rise on the external root surface during post space preparation with three different post drill systems. The results of this study partially supported the hypothesis that the temperature rise varied among the different diameter of post drills. No significant differences were found between Rebilda 1, Rebilda 2, and Relyx 1.

Different devices are used to measure temperature changes in the mouth. Measurement instruments that are based on direct contact such as subgingival thermometers and thermocouples that may have inconvenient applications of in surgery and sterilization. In addition, poor contact of the thermocouples due to irregularities in the root surface may cause inaccurate measurements. Another surface temperature measurement device, infrared thermal imaging system, requires an accurate calibration prior to use for the specific surfaces, ${ }^{[20]}$ whereas infrared thermometers can take measurements from the tissue surface and determine the only superficial temperature without contact and calibration.

Several in vitro studies have investigated the root surface temperature changes during the post space preparation..$^{[10,11,15,16,21]}$ Eriksson and Sundstrom ${ }^{[16]}$ and Saunders and Saunders ${ }^{[15]}$ measured temperature alterations on the root surface during preparation of post space used thermocouples. These studies reported temperature changes up to $57^{\circ} \mathrm{C}$ and $31^{\circ} \mathrm{C}$, respectively. Lipski et al. ${ }^{[10]}$ and Kilic et al.$^{[11]}$ measured the highest temperature changes which of $6.86^{\circ} \mathrm{C}$ and $63.53^{\circ} \mathrm{C}$ by using a thermal imaging camera under continuous water cooling. In this study, the highest temperature increases were $60^{\circ} \mathrm{C}$ and $45^{\circ} \mathrm{C}$ for Snowpost 2 and Snowpost 1, respectively. The large range of results presented in these studies might be attributed to in the different in methodologies used. The results may vary due to the device used for temperature measurement, a number of used thermocouple tip, and the teeth used. In addition, some factors may affect the temperature rise during preparation of post canal, such as the operator force, the drill type and diameter, the anatomy of the root canal, the amount of residual dentin thickness, the friction between root canal dentin and drill, the use of water coolant, and the use of new reamers. ${ }^{[10,12,15,21]}$ Lipski et al. ${ }^{[10]}$ reported that the temperature rises were lower when post space preparation was performed with water coolant $\left(6.86 \pm 1.18^{\circ} \mathrm{C}\right)$ compared to preparations without water coolant $\left(53.75 \pm 8.19^{\circ} \mathrm{C}\right)$. The authors strongly suggest that water cooling should be performed during post space preparation. Although water coolant was used, in between 11 and $20 \mathrm{~s} \mathrm{a} 40.7 \pm 12.9^{\circ} \mathrm{C}$ temperature rise was observed in this study.

In this study, single-rooted human mandibular incisors with single canals were chosen, and the 


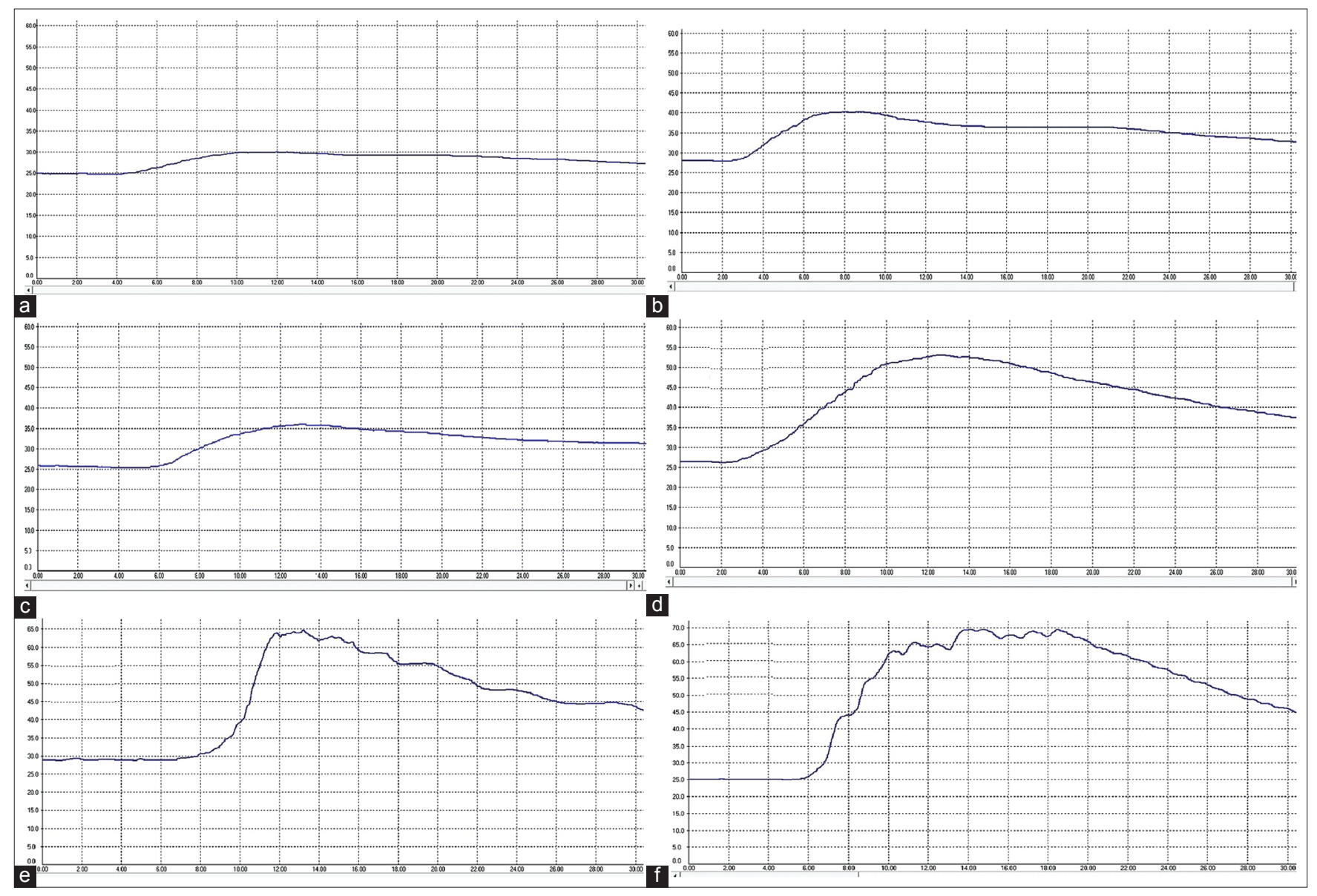

Figure 4: Temperature alteration during post space preparation with (a) Group 1, (b) Group 2, (c) Group 3, (d) Group 4, (e) Group 5, and (f) Group 6

root canal morphology was confirmed with digital radiography. Mandibular incisors are the smallest teeth in the month. In the current study, we analyzed mandibular incisor teeth because they are the most critical teeth in terms of heat conduction. ${ }^{[17]}$ In the finer dentin, more heat is passed to the outer root surface. It has been indicated that a temperature increase $>10^{\circ} \mathrm{C}$ could be harmful to the cementum, alveolar bone, and periodontal ligament tissues. ${ }^{[12,22,23]}$ Periodontal tissue damage may occur when the amount of remaining dentine is $<1 \mathrm{~mm} \cdot{ }^{[22]}$ Thus, it is important to study tooth responses to protect the periodontal ligament from high temperatures during post space preparation. However, water coolant was used in this study, harmful temperature rises were observed in all of the investigated groups. Hence, it could be expected damage to surrounding areas of the periodontal attachment.

In the current study, we chose to use the smallest and one size bigger drill in all of the post drill systems due to the temperature increase on the mandibular incisors that have an extremely narrow canal. Thus, the Rebilda size 10 (red - $0.5 \mathrm{~mm}$ apical diameter), the Rebilda size 12 (green - $0.65 \mathrm{~mm}$ apical diameter), the Relyx size 0 (white $-1.1 \mathrm{~mm}$ apical diameter), the Relyx size 1 (yellow - $1.3 \mathrm{~mm}$ apical diameter), the Snowpost size 1 (white $-1.0 \mathrm{~mm}$ apical diameter), and the Snowpost size 2 (yellow - $1.2 \mathrm{~mm}$ apical diameter) were used. There was no information about the taper of drills in the literature. In this study, the critical temperature rise was observed in all groups. Although the Relyx size 1 (yellow) has the maximum apical diameter $(1.3 \mathrm{~mm})$, the maximum temperature rise was observed in the Snowpost size 2 (yellow) and the Snowpost size 1 (white), which have 1.2 and $1.0 \mathrm{~mm}$ apical diameters, respectively. We hypothesize that because the Snowpost drills have a greater core material and remove less debris, it increases the temperature more than the other systems do. This in conjunction with the result of Lipski ${ }^{[17]}$ concerning water cooling is readily explained by the fact that the Snowpost reamer design does not allow water to flow easily in the post canal. In a previous study, the temperature rise on the mesial root surface of maxillary canines during the preparation of post space with water cooling was measured using two thermocouples. ${ }^{[8]}$ The authors used a fiberglass conical 
post drill with an apical diameter of $1.0 \mathrm{~mm}$ for the cast CPC and fiberglass post and a \#4 Peeso bur with an apical diameter of $1.3 \mathrm{~mm}$ for the prefabricated steel post. The spied of the \#4 Peeso bur has the greatest apical diameter; the minimum temperature rises were observed in these two measurement points. This finding is similar to our results. The removed or remaining dentin thickness is a determinant factor for causing temperature rises. However, in the present study, the remaining and removed dentin thickness is various due to the diameter of used drills is different. We believe that one reason for the high temperatures that occur in the groups which the greater diameter of the drill was used is thin remaining dentin thickness.

When the temperature rise was evaluated according to a time interval, the maximum temperature rise has been detected in the period from 11 to $20 \mathrm{~s}$ $\left(22.02 \pm 14.9^{\circ} \mathrm{C}\right)$ in all groups. In the $0-10 \mathrm{~s}$ period, during the initial phase of the post space preparation, the drills did not reach the WL as required. Thus, the drills prepared the middle and coronal thirds of the post space. During the period from 11 to $20 \mathrm{~s}$, drills reached the WL and had been in contact with the canal wall throughout the entire post space. This situation caused a maximum temperature increase. During the period from 21 to $30 \mathrm{~s}$ the temperature rise is less decreased with the period from 11 to $20 \mathrm{~s}$ $\left(22.02 \pm 14.9^{\circ} \mathrm{C}\right)$ in all post drill systems. This decrease probably occurred since drills reached the WL, the canal was enlarged adequately, and the drills have minimal contact with the canal wall. According to the present study results, when using drills in the full WL, the intermittent operation and use of water coolant may be suggest.

The post space preparation was performed by one investigator to simulate the clinical situation. The samples were fixed, and gently force was applied during preparation. The applied of excessive force was avoided because of it will lead excessive temperature rise.

Although the critical temperature increases were observed in all of the investigated post drill systems, the result of this in vitro study does not compare with real clinical situations. Real clinical situations considering the surrounding periodontal tissues, the periodontal and osseous blood circulation, and the oral environment have yet to be established in vitro. Additionally, the time to return to a normal temperature was not evaluated. Despite the use of water cooling, temperature increases above the critical level were observed during post space preparation. It should be considered by clinicians, the use of water coolant, intermittent operation, and application of less force during post space preparation to prevent excessive temperature rise.

\section{CONCLUSIONS}

Although water coolant was used, the critical temperature rise was observed on the external root surface in all of the post drill systems. The preparation of post space should be created with continuous water cooling and intermittently to prevent heat generation. Further clinical studies are required to assess these post drill systems for potential temperature rise risk. An infrared thermometer is a useful device for measure the temperature change and can be used for this purpose in future studies. The results of this in vitro study give the dentist flexibility in choosing the appropriate post drill systems for each tooth or patient.

\section{Financial support and sponsorship \\ Nil.}

\section{Conflicts of interest}

There are no conflicts of interest.

\section{REFERENCES}

1. Ozcan N, Sahin E. In vitro evaluation of the fracture strength of allceramic core materials on zirconium posts. Eur J Dent 2013;7:455-60.

2. Heydecke G, Peters MC. The restoration of endodontically treated, single-rooted teeth with cast or direct posts and cores: A systematic review. J Prosthet Dent 2002;87:380-6.

3. Sedgley CM, Messer HH. Are endodontically treated teeth more brittle? J Endod 1992;18:332-5.

4. Carter JM, Sorensen SE, Johnson RR, Teitelbaum RL, Levine MS. Punch shear testing of extracted vital and endodontically treated teeth. J Biomech 1983;16:841-8.

5. Faria-e-Silva AL, Pedrosa-Filho Cde F, Menezes Mde S, Silveira DM, Martins LR. Effect of relining on fiber post retention to root canal. J Appl Oral Sci 2009;17:600-4.

6. Cecchin D, de Almeida JF, Gomes BP, Zaia AA, Ferraz CC. Effect of chlorhexidine and ethanol on the durability of the adhesion of the fiber post relined with resin composite to the root canal. J Endod 2011;37:678-83.

7. Eskitascioglu G, Belli S, Kalkan M. Evaluation of two post core systems using two different methods (fracture strength test and a finite elemental stress analysis). J Endod 2002;28:629-33.

8. Amade ES, Novais VR, Roscoe MG, Azevedo FM, Bicalho AA, Soares CJ. Root dentin strain and temperature rise during endodontic treatment and post rehabilitation. Braz Dent J 2013;24:591-8.

9. Shetty PP, Meshramkar R, Patil KN, Nadiger RK. A finite element analysis for a comparative evaluation of stress with two commonly used esthetic posts. Eur J Dent 2013;7:419-22.

10. Lipski M, Mrozek J, Drozdzik A. Influence of water cooling on root surface temperature generated during post space preparation. J Endod 2010;36:713-6.

11. Kilic K, Er O, Kilinc HI, Aslan T, Bendes E, Sekerci AE, et al. Infrared thermographic comparison of temperature increases on the root 
surface during dowel space preparations using circular versus oval fiber dowel systems. J Prosthodont 2013;22:203-7.

12. Eriksson AR, Albrektsson T. Temperature threshold levels for heat-induced bone tissue injury: A vital-microscopic study in the rabbit. J Prosthet Dent 1983;50:101-7.

13. Eriksson A, Albrektsson T, Grane B, McQueen D. Thermal injury to bone. A vital-microscopic description of heat effects. Int J Oral Surg 1982;11:115-21.

14. Sauk JJ, Norris K, Foster R, Moehring J, Somerman MJ. Expression of heat stress proteins by human periodontal ligament cells. J Oral Pathol 1988;17:496-9.

15. Saunders EM, Saunders WP. The heat generated on the external root surface during post space preparation. Int Endod J 1989;22:169-73.

16. Eriksson JH, Sundström F. Temperature rise during root canal preparation - A possible cause of damage to tooth and periodontal tissue. Swed Dent J 1984;8:217-23.

17. Lipski M. In vitro infrared thermographic assessment of root surface temperatures generated by high-temperature thermoplasticized injectable gutta-percha obturation technique. J Endod 2006;32:438-41.

18. Khajuria RR, Madan R, Agarwal S, Gupta R, Vadavadgi SV, Sharma V. Comparison of temperature rise in pulp chamber during polymerization of materials used for direct fabrication of provisional restorations: An in-vitro study. Eur J Dent 2015;9:194-200.

19. Duncan AL, Bell AJ, Chu K, Greenslade JH. Can a non-contact infrared thermometer be used interchangeably with other thermometers in an adult emergency department. Australas Emerg Nurs J 2008;11:130-4.

20. Mc Cullagh JJ, Setchell DJ, Gulabivala K, Hussey DL, Biagioni P, Lamey PJ, etal. A comparison of thermocouple and infrared thermographic analysis of temperature rise on the root surface during the continuous wave of condensation technique. Int Endod J 2000;33:326-32.

21. Tjan AH, Abbate MF. Temperature rise at root surface during post-space preparation. J Prosthet Dent 1993;69:41-5.

22. Kwon SJ, Park YJ, Jun SH, Ahn JS, Lee IB, Cho BH, et al. Thermal irritation of teeth during dental treatment procedures. Restor Dent Endod 2013;38:105-12.

23. Eriksson AR, Albrektsson T, Albrektsson B. Heat caused by drilling cortical bone. Temperature measured in vivo in patients and animals. Acta Orthop Scand 1984;55:629-31.

\begin{tabular}{|l|l|}
\hline \multicolumn{2}{|c|}{ Access this article online } \\
\hline Quick Response Code: & \\
\hline
\end{tabular}

